\title{
Psychological Impact of Covid-19 among Healthcare Workers in Cameroon
}

\author{
Tendongfor Nicholas ${ }^{1 *}$, Amana Bokagne Therese Vanessa ${ }^{2}$, Kouam Talla Gilchrist Destin ${ }^{3}$, Lambou Fopa \\ Vanessa $^{2}$, Ngassam Ngassam Christie Do ${ }^{4}$, Ketchanji Alice ${ }^{5}$, Nganyewo Cynthia Atiepoh ${ }^{1}$ and Forlemu \\ Vanessa Mandaah ${ }^{2}$
}

${ }^{1}$ Department of Public Health and Hygiene, University of Buea, Buea Cameroon

${ }^{2}$ Department of Microbiology and Parasitology, University of Buea, Buea Cameroon

${ }^{3}$ Department of Biochemistry of Molecular Biology, University of Buea, Buea Cameroon

${ }^{4}$ Department of Specialised Education, University of Yaounde, Cameroon

${ }^{5}$ Department or the Control of Disease Epidemics and Pandemic, Ministry of Public health, Cameroon

\begin{abstract}
Background: Since December 2019, the world has been experiencing the Covid-19 pandemic which has claimed several thousands of lives worldwide. The healthcare workers are among the population at high risk. Evaluating the psychological impact of the Covid-19 on the mental health of healthcare workers in Cameroon is very crucial to maintain their psychological well-being, and ensure good monitoring and follow up of patients.

Methods: This study was an online survey in which electronic questionnaires were made available to healthcare workers through email and social media. The survey involved the risk perception towards Covid-19, psychological distressand the motivation of healthcare workers. The level of psychological distress was measured using the 12 -item generalised health questionnaire. Data was analysed in SPSS version 25.

Results: A majority of the healthcare workers (99.3\%) perceived Covid-19 as a major public health problem with $74.9 \%$ feeling unsaved working during the pandemic and $21 \%$ feeling as abandoning their job. Psychological distress was moderate in $63 \%$ and high in $16 \%$ of the Healthcare workers and did not vary with sociodemographic characteristics. Healthcare workers directly involved in the Covid-19 unit had a significantly higher psychological distress score compare to those not directly involved $(p=0.009)$. The motivation to carry out their duty $(74.2 \%)$, respect of the hypocrate oath $(60.9 \%)$ and serving the nation $(50.2 \%)$ were the main reasons motivating the healthcare workers to keep on performing their duty.
\end{abstract}

Conclusion: Our study highlights that healthcare workers in Cameroon are experiencing moderate to high psychological distress as a result of the Covid-19 pandemic. Therefore there is a need for psychosocial support to mitigate the distress and to ensure their well-being.

\section{Keywords}

Covid-19 pandemic, Healthcare workers, Psychological distress, Cameroon

\section{Introduction}

The Coronavirus disease (Covid-19) emerged in Wuhan City, the capital of China's Hubei province in December 2019 and has since spread globally, resulting in the ongoing 20192020 coronavirus pandemic [1]. The rapid escalation of the epidemic resulted in the World Health Organization-declared public health emergency of international concern [2]. Because of the novel nature of the virus, lack of drugs and vaccines, early diagnosis and management were crucial for containing the outbreak. In this regards, rapid diagnostic methods were developed and approved for the detection of the virus [3-5].
*Corresponding author: Tendongfor Nicholas, Department of Public Health and Hygiene, Faculty of Health Sciences, University of Buea, P.O. Box 63, Buea, Cameroon, Tel: +237-676-9276-90

Accepted: March 29, 2021

Published online: March 31, 2021

Citation: Nicholas T, Vanessa ABT, Destin KTG, et al. (2021) Psychological Impact of Covid-19 among Healthcare Workers in Cameroon. J Healthcare 4(1):47-55 
Cameroon is among the African country with a high infection rate. Recent official communication of the Minister of Public health reports more than 17586 infected cases and 393 deaths with health care workers accounting for $4.5 \%$ of the infected cases and $5.1 \%$ of the deaths [6]. One characteristic of Covid-19 is its unambiguous capacity of person-to-person transmission [7], consequently healthcare workers are at great risk of exposure. Previous disease outbreaks have illustrated the high risk of medical personnel. According to a report by the World Health Organization during the 20142016 Ebola virus epidemics in West Africa, health care workers were between 21 and 32 times more likely to be infected with Ebola than people in the general adult population [8]. In 2003, during the SARS epidemic, one index patient was found to infect 50 healthcare workers [8]. Over whelming workload, depletion or lack of personal protective equipment (PPE), wide spread media coverage, lack of specific drugs, and feelings of being in adequately supported may all contribute to the mental burden of these health care workers [9]. Through out this pandemic healthcare workers have to cope with the death of their colleagues, threat to their lives and working excessive hours in addition to their own anxiety and fear of contamination. Quarantined healthcare workers might be facing potential social isolation, and unquarantined healthcare workers experiencing social discrimination. Further more prolonged shift times as well as shortage of PPE might reduce work efficiency and increase the accident risk hence endangering health workers worldwide [10]. This absence of appropriate protective measures and equipment is a major cause of concern among medical personnel especially in developing countries with lack of a robust healthcare infra structures. Cameroon is one of the African nations experiencing a crisis in human resources for health. There are approximately 1.1 physicians and 7.8 nurses and midwives per 10,000 populations [11] which could have impact on the management of Covid-19 patients. Under such a medical and social background our healthcare workers might experience psychological problems that may impair their attention, cognitive functioning, and clinical decision-making [9]. Consequently, these could increase the occurrence of medical errors and incidents, and ultimately put patients at potential risk. Just as the world has joined efforts to manage Covid-19 infection, it will be critical not to neglect the psychological aspect of the fight against the pandemic. Hence, the mental health needs of healthcare workers in Cameroon must be addressed with the same priority of their physical health. To date, research on the immediate psychological impact of Covid-19 on healthcare workers in Cameroon is still lacking. With the progression of the pandemic, it is imperative to evaluate the mental health of our healthcare workers in order to recommend clinical and policy strategies to maintain their psychological well-being, and ensure good monitoring and follow up of patients. This study evaluated the risk perception, exposure and psychological distressof Covid-19 pandemic on healthcare workers in Cameroon.

\section{Material and Methods}

\section{Study design and participants}

This study was an online survey in which an electronic structured questionnaire was forwarded online to all health- care workers through email and social media (Whats App, Facebook and twitter) between the dates of $15^{\text {th }}$ April to $7^{\text {th }}$ May 2020. The target population included all healthcare workers of both gender residents in Cameroon aged 18 years and above. Participants received a message describing the study and directing them to an anonymous online questionnaire. They indicated their informed consent by ticking "Yes" to the question "Do you agree to participate in this survey?" Only one response per person to the questionnaire was permitted.

\section{Data collection tool}

The questionnaire consisted of two parts: Baseline socio-demographic information and a part for the psychological impact of Covid-19. The questionnaire was developed both in English and French languages. The socio-demographic variables included age, gender, marital status, region of current residence, education, job title, household size, nationality, number of years of experience and the working unit. The second part of the questionnaire comprised 34 questions divided into 5 items. 8 questions on the perception of the risk. 8 questions on the perception of healthcare professional on their working environment, 12 questions to test psychological distress and 6 questions on the motivation and how to overcome the stress.

A simplified version of the 12-item generalised health questionnaire using a dichotomous yes or no answer was used to assess the psychological distress [12]. This questionnaire is a widely accepted mental health measurement, with high reliability and validity.

The questionnaire was pretested using few respondents chosen in Buea and Yaoundé and ambiguous or poorly structure questions were adjusted. The psychological distress scores were categorized into four: No distress (0-3), moderate distress (4-6) and distress (7-9) and severe distress (10-12).

\section{Statistical analysis}

All the filled questionnaires were downloaded and analysed in SPSS version 26. Descriptive statistics was used to determine the risk perception, motivation and ways of overcoming the psychological distress. The association between the psychological distress scores and levels were compared using the Analysis of variance and Chi-square test respectively. A p-value $<0.05$ was considered significant.

\section{Ethical considerations}

Ethical approval was obtained from the Ethics Committee of the Faculty of Health Sciences, University of Buea (Ref. 2020/1204-04/UB/SG/IRB/FHS). This study was an online study and the decision to participate was individual-based. Everybody who accepts to fill the questionnaire after reading the information was considered as consenting to participate. The participants were given assurance on their personal identification and their IP address.

\section{Results}

Socio-demographic characteristics of the study participants

A total of 271 participants filled the online questionnaire 
Citation: Nicholas T, Vanessa ABT, Destin KTG, et al. (2021) Psychological Impact of Covid-19 among Healthcare Workers in Cameroon. J Healthcare 4(1):47-55

Table 1: Socio-demographic characteristics of the study participants.

\begin{tabular}{|c|c|c|c|}
\hline \multicolumn{2}{|l|}{ Designation } & \multirow{2}{*}{\begin{tabular}{|l} 
Frequency \\
125
\end{tabular}} & \multirow{2}{*}{\begin{tabular}{|l|} 
Percent \\
46.1 \\
\end{tabular}} \\
\hline Language & English & & \\
\hline & French & 146 & 53.9 \\
\hline \multirow[t]{2}{*}{ Gender } & Female & 146 & 53.9 \\
\hline & Male & 125 & 46.1 \\
\hline \multirow{4}{*}{ Age } & $21-30$ & 141 & 52.0 \\
\hline & $31-40$ & 92 & 33.9 \\
\hline & $41-50$ & 29 & 10.7 \\
\hline & $>50$ & 9 & 3.3 \\
\hline \multirow{10}{*}{ Region } & Adamawa & 4 & 1.5 \\
\hline & Centre & 79 & 29.2 \\
\hline & East & 3 & 1.1 \\
\hline & Far North & 5 & 1.8 \\
\hline & Littoral & 88 & 32.5 \\
\hline & North & 1 & 0.4 \\
\hline & North-West & 19 & 7.0 \\
\hline & South & 3 & 1.1 \\
\hline & South-West & 40 & 14.8 \\
\hline & West & 29 & 10.7 \\
\hline \multirow{6}{*}{ Job description } & Administration & 6 & 2.2 \\
\hline & Medical doctor & 166 & 61.3 \\
\hline & Nurse & 64 & 23.6 \\
\hline & Pharmacist & 5 & 1.8 \\
\hline & Support staff & 3 & 1.1 \\
\hline & Technician & 27 & 10.0 \\
\hline \multirow{4}{*}{ Years of experience } & $<2$ years & 109 & 40.2 \\
\hline & 3-5 years & 68 & 25.1 \\
\hline & $6-9$ years & 47 & 17.3 \\
\hline & $>10$ years & 47 & 17.3 \\
\hline \multirow{2}{*}{$\begin{array}{l}\text { Marital status } \\
(n=268)\end{array}$} & Married & 95 & 35.1 \\
\hline & Single & 173 & 63.8 \\
\hline \multirow{3}{*}{ Household size } & $<3$ & 94 & 34.7 \\
\hline & $3-6$ & 123 & 45.4 \\
\hline & $>6$ & 54 & 19.9 \\
\hline \multirow{2}{*}{$\begin{array}{l}\text { Directly involved in } \\
\text { the Covid-19 unit }\end{array}$} & No & 197 & 72.7 \\
\hline & Yes & 74 & 27.3 \\
\hline
\end{tabular}

among which 146 (53.9\%) were females and 141 (52.0\%) in the age group 21 to 30 years. Participants were recruited from the ten regions of Cameroon with the Littoral region more represented (32.5\%) followed by the Centre region (29.2\%). Majority of the participants were medical doctors $(61.3 \%)$ followed by nurses $(23.6 \%)$ (Table 1$)$.

Risk perception of healthcare personnel with respect to Covid-19

A majority of the healthcare workers (74.9\%) felt unsafe
Table 2: Risk perception of health care personnel with respect to Covid-19.

\begin{tabular}{|c|c|c|c|}
\hline Variable & Level & Frequency & Percent \\
\hline \multirow{2}{*}{$\begin{array}{l}\text { Covid-19 is a major health } \\
\text { problem }\end{array}$} & No & 2 & 0.7 \\
\hline & Yes & 269 & 99.3 \\
\hline \multirow{2}{*}{$\begin{array}{l}\text { Worried about getting } \\
\text { infected with Covid-19 }\end{array}$} & No & 38 & 14.0 \\
\hline & Yes & 233 & 86.0 \\
\hline \multirow{2}{*}{$\begin{array}{l}\text { Abandoning job because of } \\
\text { the Covid-19 }\end{array}$} & No & 214 & 79.0 \\
\hline & Yes & 57 & 21.0 \\
\hline \multirow{2}{*}{$\begin{array}{l}\text { Worried family or colleagues } \\
\text { could be infected }\end{array}$} & No & 7 & 2.6 \\
\hline & Yes & 264 & 97.4 \\
\hline \multirow{2}{*}{$\begin{array}{l}\text { Physical avoidance by family } \\
\text { members }\end{array}$} & No & 192 & 70.8 \\
\hline & Yes & 79 & 29.2 \\
\hline \multirow[t]{2}{*}{ Physical avoidance by friends } & No & 159 & 58.7 \\
\hline & Yes & 112 & 41.3 \\
\hline \multirow{2}{*}{$\begin{array}{l}\text { Having a colleague who } \\
\text { tested positive for Covid-19 }\end{array}$} & No & 197 & 72.7 \\
\hline & Yes & 74 & 27.3 \\
\hline \multirow{2}{*}{$\begin{array}{l}\text { Have a family member who } \\
\text { tested positive }\end{array}$} & No & 249 & 91.9 \\
\hline & Yes & 22 & 8.1 \\
\hline \multirow[t]{2}{*}{ Feeling unsafe at work } & No & 68 & 25.1 \\
\hline & Yes & 203 & 74.9 \\
\hline \multirow{2}{*}{$\begin{array}{l}\text { Received adequate training } \\
\text { on Covid-19 protocols }\end{array}$} & No & 170 & 62.7 \\
\hline & Yes & 101 & 37.3 \\
\hline \multirow{2}{*}{$\begin{array}{l}\text { Satisfied with the protocols } \\
\text { and procedures put in place }\end{array}$} & No & 56 & 75.7 \\
\hline & Yes & 18 & 24.3 \\
\hline \multirow{2}{*}{$\begin{array}{l}\text { Provided with personal } \\
\text { protective equipment }\end{array}$} & No & 99 & 36.5 \\
\hline & Yes & 172 & 63.5 \\
\hline \multirow{2}{*}{$\begin{array}{l}\text { Satisfied with protective } \\
\text { equipment provided by the } \\
\text { administration }\end{array}$} & No & 210 & 77.5 \\
\hline & Yes & 61 & 22.5 \\
\hline
\end{tabular}

working during the Covid-19 pandemic, 99.3\% perceived Covid-19 as a major public health problem. Their main concerns were: Infection of family members or colleagues (97.4\%) and risk of self-infection (86.0\%). Some healthcare workers experienced physical avoidance by their family members $(29.2 \%)$, friends (41.3\%). Few (21\%) felt like abandoning their job because of the Covid-19 pandemics in Cameroon.

With respect to their working environment, $37.3 \%$ had received adequate training with only $24.3 \%$ satisfied with the protocols and procedures put in place to fight Covid-19. Of the 74 healthcare workers directly involved in the Covid-19 unit, $51.4 \%$ received adequate training with only $24.4 \%$ were satisfied with the protocols and procedures put in place to fight Covid-19. With respect to safety, $81.1 \%$ of healthcare workers directly involved in the Covid-19 unit reported having received personal protective equipment, but only $22.5 \%$ were satisfied with the equipment (Table 2).

\section{Psychological distress in healthcare workers}

A large fraction (63\%) of the healthcare workers experi- 
enced moderate psychological distress. No healthcare workers experience severe psychological stress and only $16 \%$ experienced psychological distress (Figure 1).

\section{Association between psychological distress, so- cio-demographic and job-related characteristics}

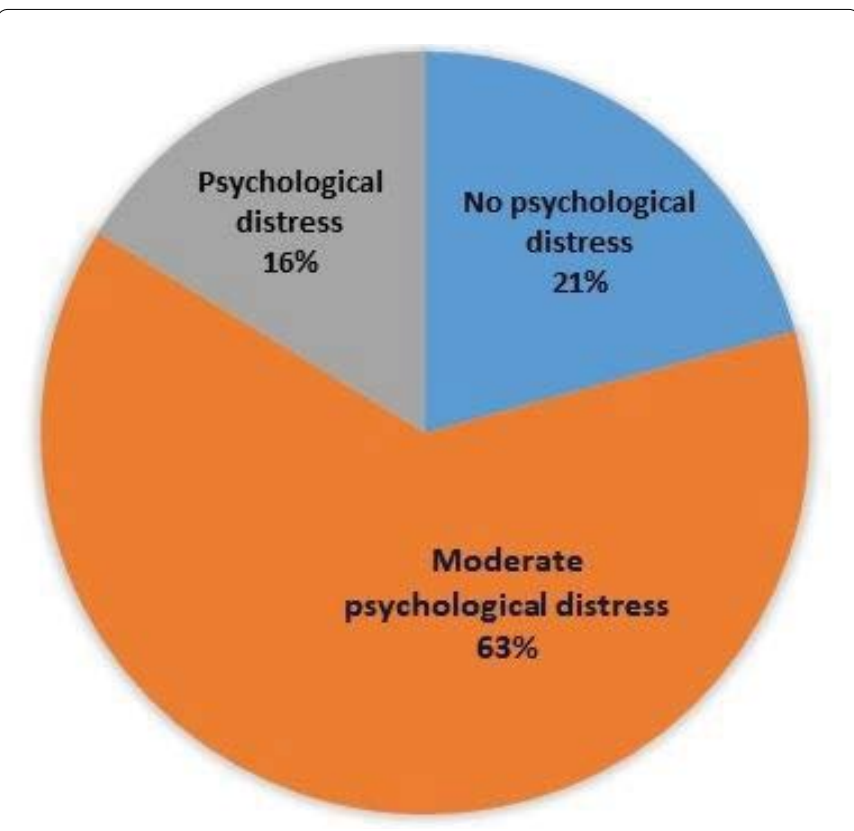

Figure 1: Psychological distress in Health care workers.
The level of psychological distress did not vary significantly with gender, age, position held in the hospital, years of experience and the direct involvement in the Covid-19 unit (Table 3).

\section{Association between psychological distress scores, socio-demographic and job-related char- acteristics}

The overall mean distress score was $4.8 \pm 1.68$. The mean score was significantly higher $(p=0.009)$ in healthcare workers directly involved in the Covid-19 unit compared to those not directly involved. The mean score was also significantly higher $(5.28 \pm 1.57)$ in healthcare workers with 3 to 5 years' experience, followed by those with more than 10 years' experience. There was no association between the mean psychological distress score and age, gender position held and marital status (Table 4).

\section{Healthcare worker motivations to continue work- ing}

Despite the high psychological distress on healthcare workers, they gave many reasons motivating them to continue working. Some of these reasons advanced included: They are performing their duty $(74.2 \%)$, they want to save live (60.9\%), they are respecting the hypocrate oath (50.2\%) and serving their nation (46.9\%). Some gave financial motivation (23.6\%) learning of new things $(29.5 \%)$ as reason for motivation (Figure 2).

Table 3: Association between the level of psychological distress, socio-demographic and job-related characteristics demographic characteristics.

\begin{tabular}{|c|c|c|c|c|c|c|}
\hline & & \multicolumn{3}{|c|}{ Level of distress } & \multirow[b]{2}{*}{ Chi-square } & \multirow[b]{2}{*}{$p$-value } \\
\hline & & Distress & Moderate & No distress & & \\
\hline \multirow[t]{2}{*}{ Gender } & Female & $29(10.7)$ & 86 (31.7) & 31 (11.4) & \multirow[t]{2}{*}{3.50} & \multirow[t]{2}{*}{0.174} \\
\hline & Male & $15(5.5)$ & 85 (31.4) & $25(9.2)$ & & \\
\hline \multirow[b]{4}{*}{ Age } & $21-30$ years & $22(8.1)$ & $89(32.8)$ & $30(11.1)$ & \multirow{4}{*}{3.81} & \multirow{4}{*}{0.733} \\
\hline & $31-40$ years & $16(5.9)$ & $60(22.1)$ & $16(5.9)$ & & \\
\hline & $41-50$ years & $5(1.8)$ & $18(6.6)$ & $6(2.2)$ & & \\
\hline & $51-60$ years & $1(0.4)$ & $4(1.5)$ & $4(1.5)$ & & \\
\hline \multirow{4}{*}{ Position } & Administration & $5(1.8)$ & $3(1.1)$ & $1(0.4)$ & \multirow{4}{*}{11.92} & \multirow{4}{*}{0.148} \\
\hline & Medical doctor & $25(9.2)$ & 107 (39.5) & $39(14.4)$ & & \\
\hline & Nurse & $9(3.3)$ & $44(16.2)$ & $11(4.1)$ & & \\
\hline & Technician & $5(1.8)$ & $17(6.3)$ & $5(1.8)$ & & \\
\hline \multirow{4}{*}{$\begin{array}{l}\text { Number of year(s) } \\
\text { of experience }\end{array}$} & $<2$ years & $16(5.9)$ & $69(25.5)$ & $24(8.9)$ & \multirow{4}{*}{6.99} & \multirow{4}{*}{0.321} \\
\hline & 3-5 years & $13(4.8)$ & $47(17.3)$ & $8(3.0)$ & & \\
\hline & $6-9$ years & $5(1.8)$ & $29(10.7)$ & $13(4.8)$ & & \\
\hline & $>10$ years & $10(3.7)$ & $26(9.6)$ & $11(4.1)$ & & \\
\hline \multirow[b]{2}{*}{ Marital status } & Married & $11(4.1)$ & $62(23.1)$ & $22(8.2)$ & \multirow[t]{2}{*}{2.01} & \multirow[t]{2}{*}{0.381} \\
\hline & Single & 31 (11.6) & $108(40.3)$ & $34(12.7)$ & & \\
\hline \multirow{2}{*}{$\begin{array}{l}\text { Directly involved in the } \\
\text { Covid-19 unit }\end{array}$} & No & $29(10.7)$ & $123(45.4)$ & 45 (16.6) & \multirow[b]{2}{*}{2.73} & \multirow[b]{2}{*}{0.256} \\
\hline & Yes & $15(5.5)$ & $48(17.7)$ & $11(4.1)$ & & \\
\hline
\end{tabular}


Citation: Nicholas T, Vanessa ABT, Destin KTG, et al. (2021) Psychological Impact of Covid-19 among Healthcare Workers in Cameroon. J Healthcare 4(1):47-55

Table 4: Association between the psychological distress scores, sociodemographic and job-related characteristics.

\begin{tabular}{|c|c|c|c|c|c|}
\hline & & n & Mean \pm SD & F-test & P-value \\
\hline \multirow[t]{2}{*}{ Gender } & Female & 146 & $4.89 \pm 1.74$ & \multirow[b]{2}{*}{0.51} & \multirow[b]{2}{*}{0.476} \\
\hline & Male & 125 & $4.74 \pm 1.62$ & & \\
\hline \multirow{4}{*}{ Age } & $21-30$ years & 141 & $4.65 \pm 1.58$ & \multirow{4}{*}{2.42} & \multirow{4}{*}{0.067} \\
\hline & $31-40$ years & 92 & $5.15 \pm 1.74$ & & \\
\hline & $41-50$ years & 29 & $4.86 \pm 1.87$ & & \\
\hline & $51-60$ years & 9 & $4.00 \pm 1.66$ & & \\
\hline \multirow{6}{*}{ Position } & Administration & 6 & $5.50 \pm 1.98$ & \multirow{6}{*}{1.15} & \multirow{6}{*}{0.335} \\
\hline & Medical doctor & 166 & $4.72 \pm 1.69$ & & \\
\hline & Nurse & 64 & $4.89 \pm 1.62$ & & \\
\hline & Pharmacist & 5 & $4.60 \pm 1.67$ & & \\
\hline & Support staff & 3 & $6.67 \pm 1.53$ & & \\
\hline & Technician & 27 & $5.00 \pm 1.71$ & & \\
\hline \multirow{4}{*}{ Years of experience } & $<2$ years & 109 & $4.55 \pm 1.60$ & \multirow{4}{*}{2.72} & \multirow{4}{*}{0.045} \\
\hline & 3-5 years & 68 & $5.28 \pm 1.57$ & & \\
\hline & $6-9$ years & 47 & $4.74 \pm 1.59$ & & \\
\hline & $>10$ years & 47 & $4.87 \pm 1.99$ & & \\
\hline \multirow[t]{2}{*}{ Marital status } & Married & 95 & $4.74 \pm 1.78$ & \multirow[b]{2}{*}{0.28} & \multirow[b]{2}{*}{0.600} \\
\hline & Single & 173 & $4.85 \pm 1.63$ & & \\
\hline \multirow{2}{*}{$\begin{array}{l}\text { Directly involved in the } \\
\text { Covid-19 unit }\end{array}$} & No & 197 & $4.66 \pm 1.68$ & \multirow[b]{2}{*}{6.93} & \multirow[b]{2}{*}{0.009} \\
\hline & Yes & 74 & $5.26 \pm 1.63$ & & \\
\hline
\end{tabular}

SD: Standard deviation

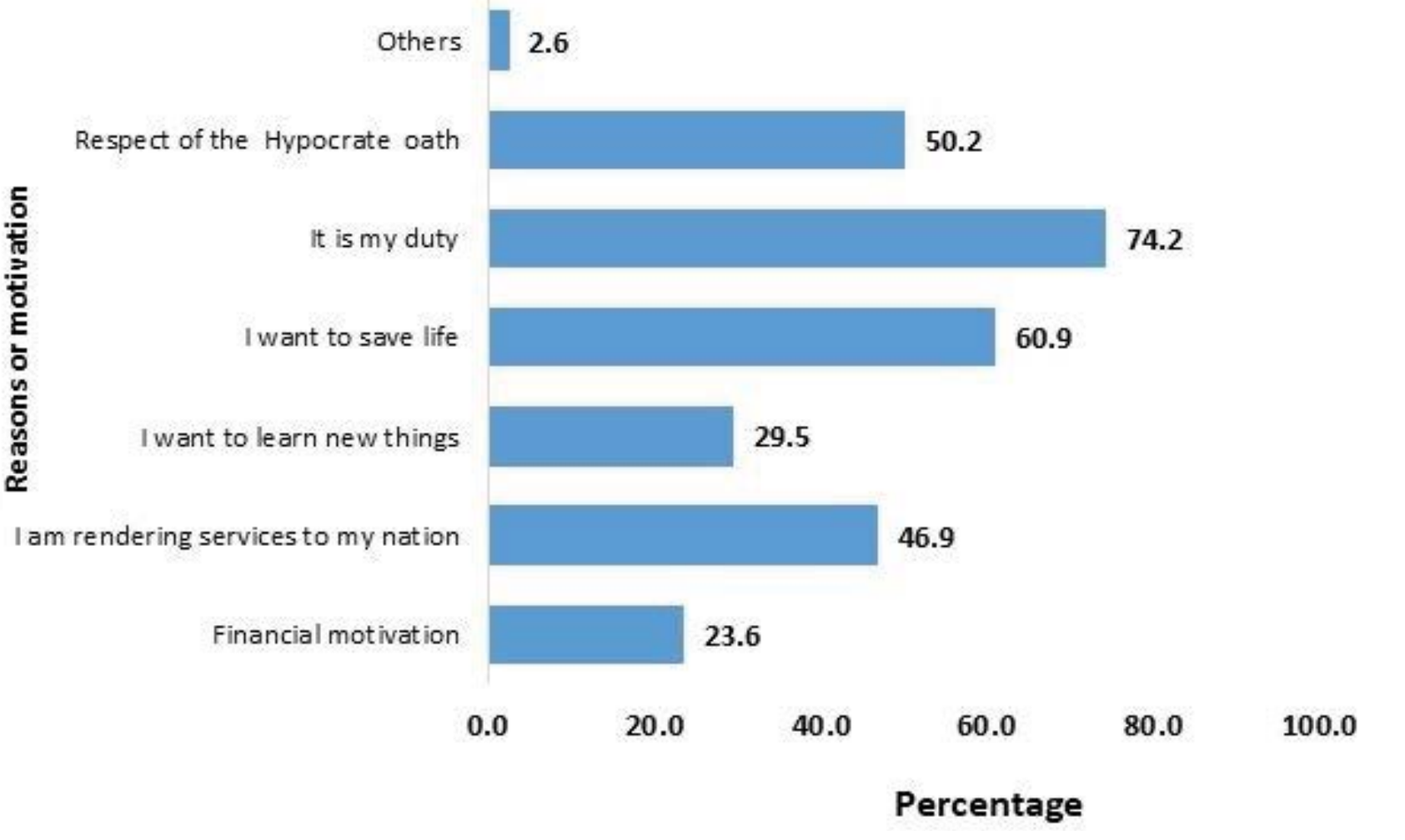

Figure 2: Health worker motivations to continue working. 


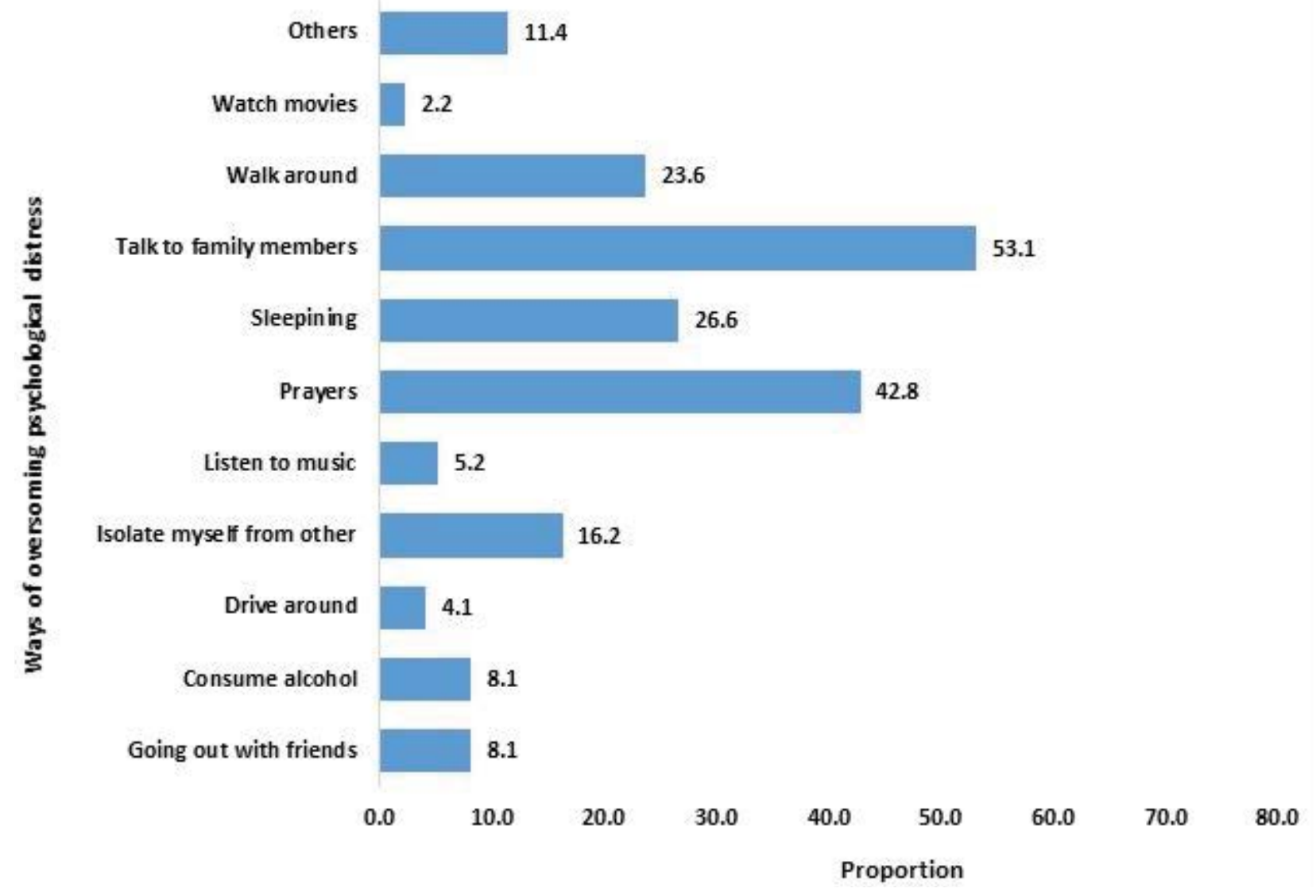

Figure 3: Ways to overcome psychological distress.

\section{Ways to overcome psychological distress}

Talking to family members $(53.1 \%)$, praying $(42.8 \%)$, sleeping $(26.6 \%)$ and walking around $(23.6 \%)$ were the main means of overcoming distress reported by healthcare workers. Other(s) means such astaking a break, shopping, taking a rest, singing, reading, crying, meeting a psychologist, eating, having sex, chatting with friends were also mentioned (Figure 3).

\section{Discussion}

The crucial role of healthcare workers during a pandemic as front liners is vital and massive, making them more susceptible to anxiety and stress due to overwhelming health care systems in addition to fear of acquiring the infection [13-15]. The World Health Organization reported that a one in ten health worker is infected with coronavirus in some countries [16]. In March 2020, 9\% of those affected with Covid-19 in Italy were health workers [17]. In May 2020, the International Council of Nurses reported that at least 90,000 healthcare workers have been infected and more than 260 nurses had in the Covid-19 pandemic [18]. Previous outbreaks and epidemics of various infectious diseases i.e. SARS-CoV-1, H1N1 influenza and Ebola virus also proved to cause significant short- and long-term psychological problems on healthcare workers $[19,20]$. Thus, this study attempted to assess the psychological impact of Covid-19 among health care workers in Cameroon during the pandemic. Understanding this impact is central in crafting effective policy responses to safeguard their psychological well-being and ensure a better follow up of patients amidst the Covid-19 public health crisis.

This study found that, majority of healthcare workers perceived Covid-19 as a threat to their life, their families and colleagues. Up to $74.4 \%$ of workers felt unsafe at their job site because of the pandemic. As noted by Maunder, et al., these emotions can be difficult to handle [21], and may result in psychological problems in the long term. Our study also found that up to $62.7 \%$ of healthcare workers have not received adequate training and protocol on Covid-19 as well as personal protective equipment. Among those who received the personal protective equipment (PPE), protocol and training, $77.5 \%$ said not to be satisfied. Shortcomings of PPE have been reported from several countries [22,23]. In China for example, inadequate staff training, shortage of personal protective equipment PPEs, reduced understanding of PPE used, and confused PPE guidance have resulted in infections and deaths among healthcare workers [24]. It is reported that more than 779 health care workers in Cameroon have contracted Covid-19 with more than $90 \%$ of the infection contracted in hospital environment [6]. This reflects that the healthcare facilities still need to strengthen the supply of medical protection resources, ensure an adequate supply of masks, goggles and protective clothing, and increase protection training for medical workers at the same time.

We only found that $21 \%$ of healthcare workers considered 
abandoning their job in order to avoid patients with Covid-19, this is much higher than a study reported in Saudi Arabia where $15 \%$ of healthcare workers considered rescheduling or changing their duty in order to avoid patients with Covid-19 [25] and less than that reported in Japan during SARS which showed that $92 \%$ of healthcare workers preferred to avoid patients with SARS [26]. In Taiwan during SARS outbreak a survey study of healthcare workers in emergency room and outpatient clinics showed that $9 \%$ of staff reported reluctance to work or had considered resignation, a similar percentage of healthcare workers developed acute stress disorder and 20\% felt that they are rejected by their neighbourhood and community $[27,28]$. Other studies highlighted the impact MERSCoV outbreak on healthcare workers who were exposed to patients and were placed in quarantine. In this study, among those healthcare workers in quarantine $7.6 \%$ reported anxiety symptoms and $16.6 \%$ reported feelings of anger $[29,30]$.

For the purpose of the present study, a modified version of the 12-item generalized health questionnaire using a dichotomous yes/no answer was chosen as a screening tool for psychological distress among health care workers [12]. It is worth mentioning that the 12 -item Generalized health questionnaire is extensively used by researchers and has been found to be reliable and well-validated [12]. Many studies have used this scale to evaluate scores of healthcare workers in different countries, showing a positive rate of $25 \%-32 \%$ [31-33]. A survey of frontline healthcare workers in Hong Kong during the period of SARS through the 12-item generalized health questionnaire showed $57 \%$ having experienced psychological distress [14]. It is reported in this study that majority of healthcare workers (79.3\%) were psychologically distressed, with the distress varying from moderate $(63.1 \%)$ to severe (16.2\%). The mean psychological distress score did not vary between male healthcare workers and female healthcare workers but varies across years of experience, with the lowest score $4.55 \pm 1.60$ observed in people with less than 2 years of experience and the highest score $5.28 \pm 1.57$ in people with 3-5 years of experience. This variation in mean scores could be attributed to the fact that, majority of respondent within 3-5 years of experience where directly involved in the Covid-19 unit.

Health care workers directly involved in the Covid-19 unit had a higher psychological distress score compare to those not directly involved. This could be simply because, those directly involved in the Covid-19 unit have greater exposure and higher risk of getting infected and are more prone to be quarantined compare to those not directly involved. This could also be due to the fact that most of the personnel chosen to belong to the group directly involved do not have any health coverage. Consequently, the proximity with a confirmed Covid-19 patient represents a great risk of contamination to the healthcare workers. Our findings are consistent with those of a recent Covid-19 study in China that demonstrated that psychological abnormality rate was much higher in the frontline healthcare workers [34]. Similar observations were reported during the H1N1 Influenza pandemic [35]. A study conducted in Singapore showed that healthcare workers caring for patients with Covid-19 reported high level of anxiety, depression and stress [36]. Increasing work de- mands on healthcare professional's conflict with their duties to family and friends, where reported to causes psychological stress [9]. Healthcare professionals reported being anxious about having to self-isolate, quarantine or becoming ill [28]. For healthcare workers, being quarantined was positively associated with minimising direct contact with patients and not reporting to work [37].

The findings gathered in our study indicated that although some of the healthcare workers (20.7\%) scored below the cut-off point of 3 and showed no psychological distress, a considerable proportion (63.1\%) scored between 4-6. This seems to suggest that a substantial portion of healthcare workers are already experiencing psychological problem and have the potential to develop and experience severe psychological distress over time. This implies psychological follow up to our healthcare workers especially those in the front line is strongly needed.

The psychological distress observed in majority of the healthcare workers though moderate could be attributed to the fact that they are worried about getting infected or having a family member or colleague infected. The lack or shortage of PPE, the avoidance of friends and family members could also account for the psychological distress. Many healthcare workers in Cameroon have been subjected to violence in their job sites by family members who can't believe their love ones died of Covid-19. We have seen many cases where medical doctors got well bitten by family members when they declared a Covid-19 patient. All this workspace violence further exacerbates the stress already put on healthcare workers during this pandemic. There is therefore an urgent need of psychological follow up to the healthcare workers as $79 \%$ of healthcare workers said they needed psychological follow up during this pandemic.

Despite the high psychological distress on healthcare worker, there were a good number of reasons that serves as motivation for health care workers to continue working during this pandemic such as performing their duty as a health care worker, saving lives, rendering services to the nation, respecting the hypocrate oath and learning new skills. Most health care workers reported that it's their duty to work whether in the presence of a pandemic or not. This could be due to the fact that everyone in the community looks on them and the lives of citizens are at risk if they don't perform their role as health care workers. These findings were similar to the findings of a study conducted in United Kingdom [38,39] on Healthcare workers' attitudes to working during influenza pandemic. Most of the study participants felt the duty to work is a professional duty that entails an obligation to work even in difficult and dangerous circumstances, because that is what they signed up for when they joined their profession. Some participants demonstrated that saving lives serves as their motivator. This could be due to the fact that they feel satisfactory when they help others in need by saving their lives. This result was similar to those of Ives, et al. [38]. Some participants demonstrated that respect for the Hypocrate oath serves as their motivation. This was similar to the findings Jonathan Ives, et al. 2009 [38], who reported that health care workers are loyal to their work ethics and in a variety 
of roles, they felt that absenteeism if one was able to work (whatever one's employment, in or out of the health service) was generally wrong and not just wrong during a pandemic.

For some of the study participants, learning new things serves as their motivator. This could be due to the fact that for most of them it was their first time to be at the forefront of such a pandemic or they have been at the forefront of a pandemic which was not as challenging as Covid-19. Thus, learning new things will help them to grow in their profession and also prepare them for subsequent pandemics. Thought majority seems not to be satisfied with their monthly income, there were still a number of reasons that motivates them to continue their job despite the challenges of the Covid-19 pandemic.

With the persistence and progression of the pandemic in Cameroon, it will be necessary to carry out a follow up study to assess the evolution of the psychological distress in the healthcare workers.

This study also highlighted the different ways by which healthcare workers overcome the distress. Talking to family members, praying sleeping and walking around were the main means of overcoming distress reported by healthcare workers. These results were in line with the WHO report on how to manage stress during the Covid-19 period by health care workers. The WHO reported that health care workers should stay in contact with family and friends. Staying connected with loved ones, including through digital methods, is one way to maintain contact, using helpful coping strategies such as ensuring sufficient rest and avoid using unhelpful coping strategies such as use of tobacco, alcohol or other drugs which can worsen the mental and physical well-being of people in the long term [40]. Also, Joshua and Kerry reported that physical activity, sleeping, medication, social support such as talking to a family member, partner, friend or any loved ones among others were healthy ways of managing stress [41].

\section{Conclusion}

Our study reveals that $99.3 \%$ of the healthcare workers in Cameroon perceived Covid-19 as a major public health problem with $74.9 \%$ feeling unsaved working during the pandemic and $21 \%$ feeling as abandoning their job. These healthcare workers experienced moderate to high psychological distress as a result of the Covid-19 pandemic. There is therefore a need for psychosocial support to mitigate the distress and to ensure their well-being.

\section{Acknowledgement}

We wish to acknowledge all the healthcare workers who took part in this study and the "Médecins du Cameroon" for participating in the online distribution of the questionnaires.

\section{Conflicts of Interests}

We the authors of this manuscript declare that there is no competing interest.

\section{References}

1. Hui DS, Azhar El, Madani TA, et al. (2020) The continuing 2019-
nCoV epidemic threat of novel coronaviruses to global healththe latest 2019 novel coronavirus outbreak in wuhan, China. International Journal of Infectious Disease 91: 264-266.

2. World Health Organization (2020) Statement on the second meeting of the international health regulations (2005). Emergency Committee regarding the outbreak of novel coronavirus (2019 nCoV).

3. Shirato K, Nao N, Katano H, et al. (2020) Development of genetic diagnostic methods for detection for novel coronavirus 2019(nCoV-2019) in Japan. Japanese Journal of Infectious Diseases 73: 304-307.

4. Liu R, Fu A, Deng Z, et al. (2020) Promising methods for detection of novel coronavirus SARS-CoV-2. View 1: 1-4.

5. Seo G, Lee G, Kim MJ, et al. (2020) Rapid detection of COVID-19 causative virus (SARS-CoV-2) in human nasopharyngeal swab specimens using field-effect transistorbased biosensor. ACS Nano 14: 5135-5142.

6. Cameroon Situation Report (SITREP) (2020) Centre des operations d'urgence de sante publique. Période du 42.

7. Chang JF-W, Yuan S, Kok K-H, et al. (2020) A familial cluster of pneumonia associated with the 2019 novel coronavirus indicating person-to-person transmission: A study of a family cluster. Lancet 395: 514-523.

8. Sadhegi NB, Wen LS (2020) Novel coronavirus should prompt examination of impact of outbreaks on health care workers. Health Affairs Blog.

9. Lai J, Ma S, Wang Y, (2020) Factors associated with mental health outcomes among health care workers exposed to coronavirus disease 2019. Psychiatry 3: e203976.

10. (2020) Shortage of personal protective equipment endangering health care workers worldwide. World Health Organization.

11. WHO (2010) AHWO Cameroon Fact Sheet.

12. Goldberg DP, Gater R, Sartorius N, et al. (1997) The validity of two versions of the GHQ in the WHO study of mentalillness in general health care. Psychological Medicine 27: 191-197.

13. Wilson N, Baker M, Crampton P, et al. (2005) The potential impact of the next influenza pandemic on a national primary care medical workforce. Hum Resour Health 3: 7.

14. Tam CWC, Pang EPF, Lam LCW, et al. (2004) Severe acute respiratory syndrome (SARS) in Hong Kong in 2003: Stress and psychological impact among frontline healthcare workers. Psychol Med 34: 1197-1204.

15. Koh D, Lim M-K, Chia S-E (2003) SARS: Health care work can be hazardous to health. Occup Med 53: 241-243.

16. McAlonan GM, Lee AM, Cheung V, et al. (2007) Immediate and sustained psychological impact of an emerging infectious disease outbreak on health care workers. Can J Psychiatry 52: 241-247.

17. Wu P, Fang Y, Guan Z, et al. (2009) The psychological impact of the SARS epidemic on hospital employees in China: exposure, risk perception, and altruistic acceptance of risk. Can J Psychiatry 54: 302-311.

18. Li L, Wan C, Ding R, et al. (2015) Mental distress among liberian medical staff working at the china ebola treatment unit: A cross sectional study. Health Qual Life Outcomes 13: 156.

19. (2020) How to protect health workers now: WHO Covid-19 briefing. World Economic Forum. 
Citation: Nicholas T, Vanessa ABT, Destin KTG, et al. (2021) Psychological Impact of Covid-19 among Healthcare Workers in Cameroon. J Healthcare 4(1):47-55

20. Mitchell G (2020) Nurses among confirmed deaths from Covid-19 around the world. Nursing Times.

21. Maunder R, Hunter J, Vincent L, et al. (2003) The immediate psychological and occupational impact of the 2003 SARS outbreak in a teaching hospital. CMAJ 168: 1245-1251.

22. Taegtmeyer M, Wingfield T (2020) Healthcare workers and coronavirus: Behind the stiff upper lip we are highly vulnerable.

23. (2020) Begging for Thermometers, Body Bags, and Gowns: US. Health care workers are dangerously ill-equipped to fight Covid-19. Time.

24. Wang J, Zhou M, Liu F (2020) Reasons for healthcare workers becoming infected with novel coronavirus disease 2019 (Covid-19) in China. Journal of Hospital Infection 105: 100-101.

25. Alkhamees AA, Alrashed SA, Alzunaydi AA, et al. (2020) The psychological impact of Covid-19 pandemic on the general population of Saudi Arabia. Comprehensive Psychiatry 102: 152192.

26. Imai T, Takahashi K, Hasegawa N, et al. (2005) SARS risk perceptions in healthcare workers. Jpn Emerg Infect Dis 11: 404-410.

27. Bai YM, Lin C-C, Lin C-Y, et al. (2004) Survey of stress reactions among health care workers involved with the SARS outbreak. Psychiatr Serv 55: 1055-1057.

28. Brooks SK, Webster RK, Smith LE, et al. (2020) The psychological impact of quarantine and how to reduce it: Rapid review of the evidence. Lancet 395: 912-920.

29. Jeong H, Yim HW, Song Y-J, et al. (2016) Mental health status of people isolated due to middle east respiratory syndrome. Epidemiol Health 38: e2016048.

30. Kim JY, Song JY, Yoon YK, et al. (2015) Middle east respiratory syndrome infection control and prevention guideline for healthcare facilities. Infect Chemother 47: 278-302.

31. Wang JL, Yin WY, Zhang HL, et al. (2019) Study on the general mental health status andinfluencing factors of chinese medical team members. Zhonghua Liu Xing Bing Xue Za Zhi 40: 574-579.
32. Firth-Cozens J (1987) Emotional distress in junior house officers. British medical journal 95: 533-536.

33. Ramirez AJ, Graham J, Richards MA, et al. (1995) Burnout and psychiatric disorder among cancer clinicians. British journal of cancer 71: 1263-1269.

34. Wen L, Wang H, Lin Y, et al. (2020) Psychological status of medical workforce during the COVID-19 pandemic: A cross-sectional study. Psychiatry Res 288: 112936.

35. Verma S, Mythily S, Chan Y, et al. (2004) Post-SARS psychological morbidity and stigma among general practitioners and traditional chinese medicine practitioners in Singapore. Ann Acad Med Singapore 33: 743-748.

36. Tan BYQ, Chew NWS, Lee GKH, et al. (2020) Psychological Impact of the Covid-19 pandemic on health care workers in Singapore. Annals of Internal Medicine.

37. Marjanovic Z, Greenglass ER, Coffey S (2007) The relevance of psychosocial variables and working conditions in predicting nurses' coping strategies during the SARS crisis: An online questionnaire survey. International Journal of Nursing Studies 44: 991-998.

38. Ives J, Greenfield S, Parry JM, et al. (2009) Healthcare workers attitudes to working during pandemic influenza: A qualitative study. BMC Public Health 9: 56.

39. Damer S, Draper H, Wilson S, et al. (2010) Healthcare workers' perceptions of the duty to work during an influenza pandemic. Journal of Medical Ethics 36: 12-18.

40. World Health Organization (WHO) (2020) Mental health and psychosocial considerations during the Covid-19 outbreak.

41. Joshua JBF, Kerry K (2015) Stress Management. ( $2^{\text {nd }}$ edn), Kendall Hunt.

DOI: $10.36959 / 569 / 462$

Copyright: (c) 2021 Nicholas T, et al. This is an open-access article distributed under the terms of the Creative Commons Attribution License, which permits unrestricted use, distribution, and reproduction in any medium, provided the original author and source are credited. 